\title{
Mathematical Modeling and Experimental Validation of Mixed Metal Oxide Thin Film Deposition by Spray Pyrolysis
}

\author{
S. M. Navid Khatami ${ }^{1}$, Olusegun J. Ilegbusi ${ }^{*}$, Leonid I. Trakhtenberg² \\ ${ }^{1}$ Department of Mechanical and Aerospace Engineering, University of Central Florida, Orlando, FL, USA \\ ${ }^{2}$ Semenov Institute of Chemical Physics, Russian Academia of Sciences, Moscow, Russia \\ Email: ${ }^{*}$ ilegbusi@ucf.edu
}

Received 9 November 2014; revised 29 November 2014; accepted 16 December 2014

Copyright (C) 2015 by authors and Scientific Research Publishing Inc.

This work is licensed under the Creative Commons Attribution International License (CC BY). http://creativecommons.org/licenses/by/4.0/

c) (7) Open Access

\begin{abstract}
The deposition of metal oxide films using Spray Pyrolysis Technique (SPT) is investigated through mathematical and physical modeling. A comprehensive model is developed in the processes including atomization, spray, evaporation, chemical reaction and deposition. The predicted results including particle size and film thickness are compared with the experimental data obtained in a complementary study. The predicted film thickness is in a good agreement with the measurements when the temperature is high enough for the chemical reaction to proceed. The model also adequately predicts the size distribution when the nanocrystals are well-structured at controlled temperature and concentration.
\end{abstract}

\section{Keywords}

ZnO Oxide Film, Mixed Metal Oxides, Film Growth, Modeling, Spray Pyrolysis

\section{Introduction}

Mixed metal oxide films are widely applied in solar cells, optoelectronics, gas sensors etc. [1] [2]. The synthesized film is typically composed of mixtures of electron donors (e.g. $\mathrm{In}_{2} \mathrm{O}_{3}$ ) and electron acceptors (e.g. $\mathrm{ZnO}$, $\mathrm{SnO}_{2}$ ). Several techniques have been used for synthesis of mixed metal oxide films such as Spray Pyrolysis Technique (SPT), Chemical Vapor Deposition (CVD), Sol-gel [3]. In order to synthesize the film with the desired properties, the morphology of the film must be controlled and largely predictable. The objective of this study is to develop a model for systematic investigation of the processes involved in mixed metal oxide deposi-

*Corresponding author.

How to cite this paper: Khatami, S.M.N., Ilegbusi, O.J. and Trakhtenberg, L.I. (2015) Mathematical Modeling and Experimental Validation of Mixed Metal Oxide Thin Film Deposition by Spray Pyrolysis. Materials Sciences and Applications, 6, 68-77. http://dx.doi.org/10.4236/msa.2015.61009 
tion by SPT in order to predict the film morphology.

SPT is a solution based method [4] utilizing thermal deposition of a metal precursor. It involves primarily five processes namely atomization, spray, evaporation, chemical reaction and film growth. Several approaches have been used to develop mathematical methods of the process. One approach involves descriptive models which mostly consider the physics of the process. Different spray methods and the deposition stages were studied by using this approach [5] and a conceptual model of the process was developed in previous study [6].

Evaporation and particle growth have been modeled using different approaches. The formation of solid particles in spray synthesis has been investigated [7] and a model was suggested for droplet evaporation and the transient droplet physical properties [8]. An evaporation model of droplets was developed to predict the size and composition of precipitates as the chemical reaction progressed [9]. The study demonstrated that increasing the temperature will increase the final particle size. Evaporation and drying for SPT was modeled and validated with the deposition of different materials [10].

Computational Fluid Dynamics (CFD) approach has been applied to study SPT deposition process. CFD was used to model spray droplets and the effect of heated environment on droplet characteristics [11]. A similar model was developed to investigate the evaporation phenomena in ethanol-NaCl-water droplet [12]. The atomization and evaporation of droplets were investigated, including the effect of swirl on the spraying of droplets onto a heated substrate in previous studies [13] [14].

Modeling the reaction and the film growth has been considered in some recent studies. These studies considered the variation of concentration within the droplets by defining the characteristic time constants. A comprehensive model which includes the evaporation and reaction stages was developed and validated for deposition of $\mathrm{TiO}_{2}$ nano particles [15]. The atomization and decomposition processes were also considered. Droplet transport and interaction between droplets was assumed as Chemical Vapor Deposition phenomena [16]. The precursor was exposed to a heated substrate through inert gas and the film deposition was independent of direction, which facilitated model formulation. The model was validated by experimental results from deposition of tin chloride on silicon wafer substrate.

Considering that the flow rates of gas and precursor in both CVD and SPT methods can be controlled [17] for the same range of temperature [18], a novel approach is proposed in this paper to model the deposition of metal oxide thin films. Specifically, SPT and CVD can be assumed to be analogous when the solvent evaporates before the droplet hits the substrate, and subsequently reaches the surface in the vapor phase. The temperature of the substrate is considered at the range for which columnar film is expected to grow. This temperature permits the assumption that the residence and reaction times are on the same order.

\section{Formulation}

Figure 1 shows a schematic sketch of the spray pyrolysis experimental setup [19]. This process involves three major steps [19]: 1) Atomization of a precursor solution in the nozzle to tiny droplets; 2) Spraying of the droplets onto a preheated substrate; and 3) Synthesis and adherence of film to the substrate due to chemical reaction and thermal decomposition.

A comprehensive mathematical model of the SPT process can be considered in two broad categories. The first involves the atomization process and the second involves collectively the evaporation, chemical reaction and the film growth processes. The parameters associated with each process are listed in Table 1.

The major parameters associated with each process are shown in Figure 2. First, a spray model is developed to predict droplet diameter before reaching the substrate $\left(d_{d}\right)$. The details of the spray model have been presented in previous papers [13] [20]. This CFD model also is used to determine the pressure and temperature distribution within the domain. The initial droplet mass $\left(m_{i}\right)$ can be calculated from the droplet diameter and used in the subsequent evaporation model.

\subsection{Evaporation}

The evaporation rate of a single droplet is derived from mass conservation equation and simplified by assuming that the temperature inside the droplet reaches steady state condition. Therefore, a pseudo-steady state evaporation is proposed [15]. The solvent evaporation rate is determined by the decreasing droplet mass $(m)$ and can be formulated as: 
Table 1. Spray pyrolysis process models.

\begin{tabular}{|c|c|c|c|}
\hline Model & Type & Input & Output \\
\hline Spray & CFD model & $\begin{array}{ll}T_{s} & \text { (Substrate temperature) } \\
V_{i} & \text { (Initial droplet velocity) }\end{array}$ & $\begin{array}{cl} & P \text { (Pressure) } \\
& T \text { (Temperature) } \\
m_{i} & \text { (Initial droplet mass) } \\
d_{d} & \text { (Initial droplet diameter) }\end{array}$ \\
\hline Evaporation & Math model & $\begin{array}{cc}P \text { (Pressure) } & T \text { (Temperature) } \\
m_{i} & \text { (Initial droplet mass) } \\
d_{d} & \text { (Initial droplet diameter) }\end{array}$ & $m_{f} \quad$ (Final droplet mass) \\
\hline $\begin{array}{l}\text { Decomposition/ } \\
\text { Reaction }\end{array}$ & Math model & $\begin{array}{c}T \text { (Temperature) } \\
C \text { (Initial concentration of precursor) derived from } m_{f}\end{array}$ & $\begin{array}{c}x_{R, f} \quad \text { (Final fraction of precursor reacted) } \\
d_{f} \quad \text { (Final droplet diameter) }\end{array}$ \\
\hline $\begin{array}{l}\text { Deposition/ } \\
\text { Growth }\end{array}$ & Math model & $D_{i}$ (Initial film thickness) derived from $d_{f}$ & $D_{f} \quad$ (Final film thickness) \\
\hline
\end{tabular}

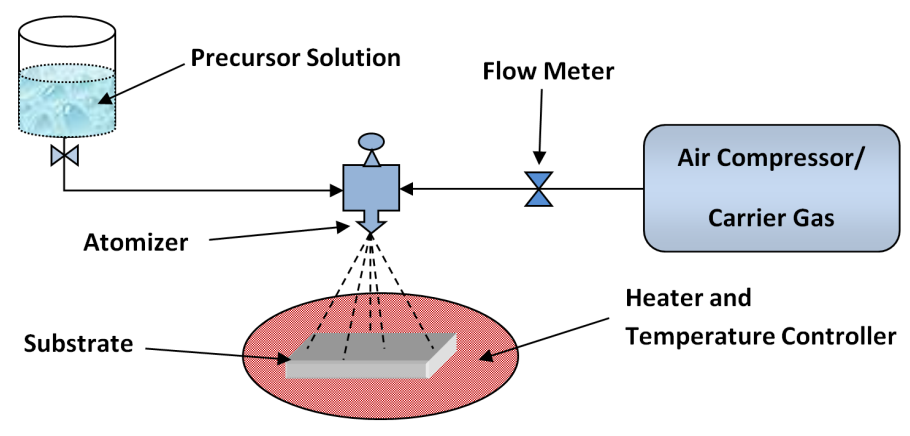

Figure 1. Schematic sketch of chemical spray pyrolysis process.

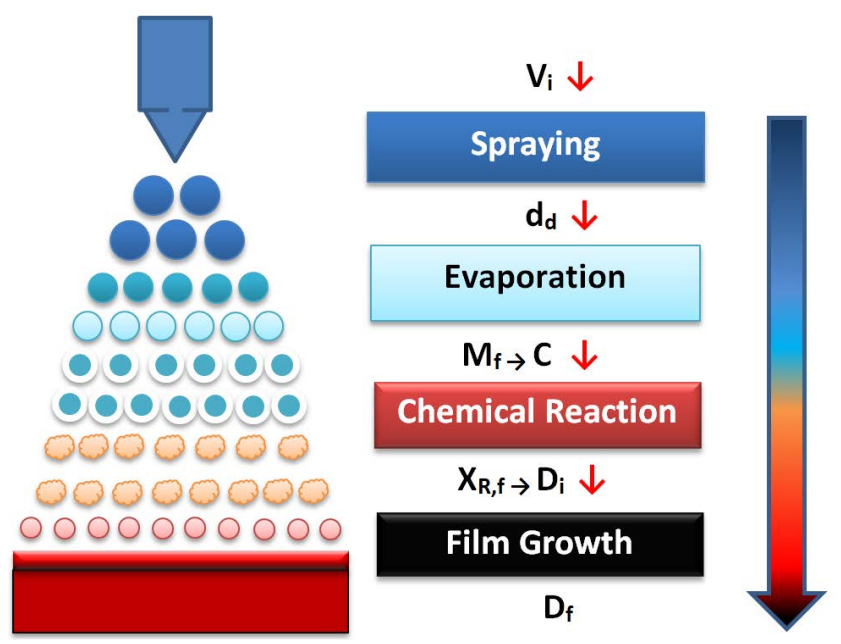

Figure 2. Schematic view of spray pyrolysis stages.

$$
\frac{\mathrm{d} m}{\mathrm{~d} t}=\frac{2 \pi d_{d} D_{v} M}{N_{A}}\left(n_{g}-n_{\text {sat }}\right) \varphi
$$

where $D_{v}$ is the diffusion coefficient of solvent vapor in air, $N_{A}$ is Avogadro's constant $\left(6.0221413 \times 10^{23}\right.$ 1/mole), $M$ is the molecular weight of water, and $n_{g}$ and $n_{\text {sat }}$ are the vapor concentrations at the droplet surface and in the surrounding air, respectively [15]. Initial mass $\left(m_{i}\right)$ is determined from CFD modeling of 
spray for a droplet at the substrate. This value considers the mass of water inside the droplet. In the specific experiment considered for validation, the precursor comprised $1 \% \mathrm{ZnCl}_{2}$ (for $\mathrm{ZnO}$ single oxide) and $5 \% \mathrm{ZnCl}_{2}+$ $95 \% \mathrm{In}\left(\mathrm{NO}_{3}\right)_{3}$ (for $\mathrm{ZnO}+\mathrm{In}_{2} \mathrm{O}_{3}$ mixed oxide) of the total mass of droplet. Therefore, the mass of precursor can be neglected inconsideration of the total mass at this stage. The parameter $\varphi$ in Equation (1) is the Knudsen correction which allows for the effect of transport when the size of droplet is on the order of the mean free path of molecules in air $(\lambda \sim 68 \mathrm{~nm})$ :

$$
\varphi=\frac{2 \lambda+d_{d}}{d_{d}+5.33\left(\frac{\lambda^{2}}{d_{d}}\right)+3.42 \lambda}
$$

where $d_{d}$ is the droplet diameter.

The vapor concentration can be calculated as:

$$
\begin{aligned}
& n_{g}=\frac{X_{w} P_{g}}{k_{B} T_{\text {sat }}} \\
& n_{\text {sat }}=\frac{X_{w} P_{\text {sat }}}{k_{B} T_{\text {sat }}}
\end{aligned}
$$

where $P$ is the pressure and $x_{w}$ is the mole fraction of solvent (water). The parameter $D_{v}$ can be defined as [15]:

$$
D_{v}=\frac{1.13 \times 10^{-5} \cdot T^{2.159}}{P}
$$

Since $D_{v}, n_{g}$ and $n_{\text {sat }}$ are dependent on surrounding air pressure $(P)$ and temperature $(T)$, the temperature and pressure are determined by CFD modeling of spray using the FLUENT software package which was developed in previous papers [13] [20]. The substrate temperature is fixed at $400^{\circ} \mathrm{C}$ as a reference.

By solving Equation (1) in MATLAB, the final mass $\left(m_{f}\right)$ inside the droplet can be determined. This value can be used to calculate the initial droplet diameter $\left(d_{i}\right)$ and the concentration of initial precursor $(C)$ for the next stage.

\subsection{Decomposition/Reaction}

The pyrolysis of the precipitate starts before the precipitate reaches the substrate and nucleation and growth of thin films on the substrate occurs later. Subsequently, a continuous thin layer of metal oxide is synthesized by the growth of the nuclei. The desired condition is for the droplet to approach the substrate when the solvent has been largely removed [21].

A chemical reaction (thermal decomposition) occurs during spray pyrolysis in addition to the physical processes of evaporation and drying [15]. The chemical reaction for the system considered can be formulated as:

$$
\begin{gathered}
\mathrm{ZnCl}_{2}+\mathrm{H}_{2} \mathrm{O} \rightarrow \mathrm{ZnO}+2 \mathrm{HCl}_{(\mathrm{g})} \\
2 \mathrm{In}\left(\mathrm{NO}_{3}\right)_{3}+3 \mathrm{H}_{2} \mathrm{O} \rightarrow \mathrm{In}_{2} \mathrm{O}_{3}+6 \mathrm{H}\left(\mathrm{NO}_{3}\right)
\end{gathered}
$$

Since the decomposition rates of precursors are determined by the heating rate, a thermal analysis is performed at different heating rates to obtain the kinetic reaction equation as a function of activation energy [15]. Therefore, the general kinetic equation can be expressed as [15]:

$$
\frac{\mathrm{d}_{x_{R}}}{\mathrm{~d} t}=A \mathrm{e}^{\left(-E_{a} / R T\right)} f\left(x_{R}\right)
$$

where $\frac{\mathrm{d}_{x_{R}}}{\mathrm{~d} t}$ is the reaction rate, $R$ is gas constant $(8.3144621 \mathrm{~J} / \mathrm{mol} \cdot \mathrm{K}), \quad x$ is the fraction of precursor reacted $\left[\mathrm{ZnCl}_{2}\right.$ and/or $\left.\operatorname{In}\left(\mathrm{NO}_{3}\right)_{3}\right]$, and $f\left(x_{R}\right)$ is the function of fraction reacted which depends on the mechanism of the decomposition reaction. This function represents the theoretical kinetic equation of the decomposition mechanism and it can be defined by normal grain growth model: $f\left(x_{R}\right)=\left(1-x_{R}\right)^{n}$ where $n=1.25$ is a 
function of reaction order [15]. In Equation (8), $A$ is the pre-exponential factor and $E_{a}$ is the activation energy which can be determined from the Arrhenius kinetic reaction equation. By solving the differential Equation (8), the final $x_{R} \quad\left(x_{R, f}\right)$ can be found which is the fraction of the precursor reacted at the final stage.

The final diameter after chemical reaction is derived from the one-droplet to one-particle principle in spray pyrolysis [15] thus:

$$
d_{f}=d_{d}\left(\frac{C \cdot M_{p}}{\rho_{p}}\right)^{1 / 3}
$$

where $d_{f}$ is the final particle diameter, $d_{i}$ is initial droplet diameter, $C$ is concentration of initial precursor, $M_{p}$ is molecular weight of the generated particle, and $\rho_{p}$ is the density of the generated particle ( $\mathrm{ZnO}$ in single oxide and $\mathrm{ZnO}+\mathrm{In}_{2} \mathrm{O}_{3}$ in mixed oxide). Since only a fraction of precursor is involved in the chemical reaction at this stage, the final droplet diameter needs to be modified accordingly. Therefore, the final droplet size is corrected using the $x_{R, f}$ factor. In effect, when $x_{R, f}=1$, the final $d_{f}$ is equal to the calculated diameter, and when $x_{R, f}=0$, there is no particle created and $d_{f}=0$.

\subsection{Deposition/Growth}

The growth rate in a spray deposition process is linearly dependent on spray time and logarithmically dependent on the substrate temperature [16]. The experimental results of the study are in good agreement with the Arrhenius expression. Therefore the rate can be represented by:

$$
\frac{\mathrm{d} D}{\mathrm{~d} t}=A_{1} \mathrm{e}^{\left(-E / k_{B} T\right)}
$$

where $D$ is the film thickness, $A_{1}$ is the growth rate coefficient, $T$ is temperature, $t$ is time and $k_{B}$ is the Boltzmann constant $\left(=1.3806488 \% \times 10^{-23} \mathrm{~m}^{2} \cdot \mathrm{kg} / \mathrm{s}^{2} \cdot \mathrm{K}\right)$. Based on the experimental results, the following parameters were used to solve Equation (10): $A_{1}=3.1 \mu \mathrm{m}, t=30 \mathrm{~s}, T=400^{\circ} \mathrm{C}, E=0.427 \mathrm{eV}$. Since the amount of indium nitrate in the mixture is less than $20 \%$, the same growth rate coefficient can be used for the mixed oxide cases.

The initial film thickness $\left(D_{i}\right)$ is derived from the reaction stage. Specifically, the final droplet diameter $\left(d_{f}\right)$ at that stage is assumed to be the same as the initial film thickness, assuming a spherical particle shape. The final film thickness $\left(D_{f}\right)$ is predicted subsequently by solving Equation (10). It should be remarked that since the precursor solution used for the spray is typically dilute, the above model is expected to be valid for both single and mixed oxides.

An experimental study was conducted to validate the modeling results. In the experiment, the precursor solution is sprayed onto a heated alumina substrate using spray pyrolysis. The precursor solution consists of a mixture of $\mathrm{ZnCl}_{2}$ and $\mathrm{In}\left(\mathrm{NO}_{3}\right)_{3}$ dissolved in water for synthesis of $\mathrm{ZnO}+\mathrm{In}_{2} \mathrm{O}_{3}$ and only $\mathrm{ZnCl}_{2}$ for $\mathrm{ZnO}$ single oxide. The optimum processing conditions are strongly dependent on the composition of the precursor solution.

The deposited single and mixed oxide thin films are subsequently characterized by Scanning Electron Microscopy (SEM) for the particle size and film thickness. SEM combines high spatial resolution with a wide field of view to improve accuracy [22]. Image processing techniques are applied on the SEM micrographs to determine particle size distribution. Specifically, the mean diameter of each particle is obtained from which the average particle size is determined for all particle dimensions. The mean area of particles $(\bar{A})$ is calculated by considering the total number of particles and the space intervals, thus [23]:

$$
\bar{A}=A+\left(\sum f \mathrm{~d} / N\right) i
$$

where $\bar{A}$ is the actual mean area, $A$ is the assumed mean area, $i$ is the class interval between particles, $d$ is deviation of midpoint from assumed mean, and $N$ is total number of particles considered. Table 2 summarizes the input data used for the experiments.

\section{Results}

\subsection{Film Thickness}

Figure 3 shows the predicted variation of $\mathrm{ZnO}$ film thickness with deposition duration. The film initially grows 
Table 2. Experimental parameters used for deposition of $\mathrm{ZnO}$ and $\mathrm{Zno}+\mathrm{In}_{2} \mathrm{O}_{3}$ films.

\begin{tabular}{ccc}
\hline Deposited metal oxide & Concentration (mol/lit) & Temperature $\left({ }^{\circ} \mathbf{C}\right)$ \\
\hline $\mathrm{ZnO}$ & 0.1 & 350 \\
$\mathrm{ZnO}$ & 0.1 & 400 \\
$\mathrm{ZnO}$ & 0.2 & 400 \\
$\mathrm{ZnO}$ & 0.3 & 400 \\
$25 \mathrm{wt} \% \mathrm{ZnO}+75 \mathrm{wt} \% \mathrm{In}_{2} \mathrm{O}_{3}$ & 0.1 & 400 \\
$80 \mathrm{wt} \% \mathrm{ZnO}+20 \mathrm{wt} \% \mathrm{In}_{2} \mathrm{O}_{3}$ & 0.1 & 400 \\
\hline
\end{tabular}

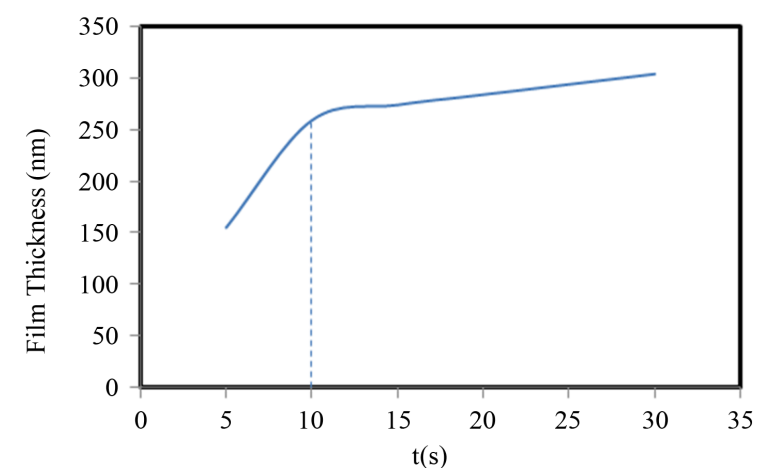

Figure 3. Predicted variation of $\mathrm{ZnO}$ film thickness with deposition time $\left(T=400^{\circ} \mathrm{C}, C=0.2 \mathrm{~mol} / \mathrm{lit}\right)$.

rapidly and after a certain duration ( $10 \mathrm{~s}$ ), becomes gradual. The result illustrates the role of mass diffusion in the growth of crystalline structures. This observed trend may be attributed to space limitation on the substrate surface and pressure from adjacent growing particles which subsequently limit the growth rate. At long time duration, the growth rate is limited by diffusion at a constant level in the consensus of previous studies [24].

Figure 4 shows the predicted variation of $\mathrm{ZnO}$ film thickness with substrate temperature. Increasing the substrate temperature enhances the growth of particles on the surface. This trend is consistent with the direct influence of temperature on both diffusion and chemical reaction. It should be noted that the threshold deposition time of $10 \mathrm{~s}$ of previous Figure 3 which produced a film thickness of $272 \mathrm{~nm}$ corresponds to a temperature of $400^{\circ} \mathrm{C}$ in Figure 4.

Table 3 compares the film thickness of $\mathrm{ZnO}$ films obtained from modeling and experiments at two substrate temperatures. The experiment was performed with deposition duration of $10 \mathrm{~s}$ which is the threshold deposition time obtained from the model (Figure 3). The model predicts the film thickness on the same order as the experiment and the accuracy is quite good $\left(<3 \%\right.$ error) at the higher temperature of $400^{\circ} \mathrm{C}$. The improved model accuracy at higher temperature is attributed to the heat loss in the experiment which impedes film growth. Some of the heat loss is compensated at the higher temperatures. These results are also consistent with Figure 3 and Figure 4. Thus the proposed model has the potential to successfully predict the optimum processing parameters for the film synthesis.

\subsection{Particle Size}

Figures 5(a)-(c) show the SEM micrographs of single ZnO oxides processed at defined temperature and different concentrations. At low concentration ( $C=0.1 \mathrm{~mol} /$ lit) (Figure 5(a)), small spherical crystallites are formed that agglomerate at the surface in the shape of powder. The average particle size is $112 \mathrm{~nm}$ which is in the consensus of previous studies [25]-[27].

The properties of particles change by increasing the concentration. The grain size increases with increase in the amount of precursor dissolved in solution in Figure 5(b) as was also observed in previous studies [28] [29]. The film is mostly homogenous with average nanoparticle size of about $119 \mathrm{~nm}$. The particles exhibit the 
Table 3. Predicted and measured thickness of $\mathrm{ZnO}$ films.

\begin{tabular}{ccccc}
\hline Temperature $\left({ }^{\circ} \mathbf{C}\right)$ & Concentration (mol/lit) & Time (s) & Measured film thickness (nm) & Predicted film thickness (nm) \\
\hline 350 & 0.1 & 10 & 112 & 169 \\
400 & 0.2 & 10 & 233 & 214 \\
\hline
\end{tabular}

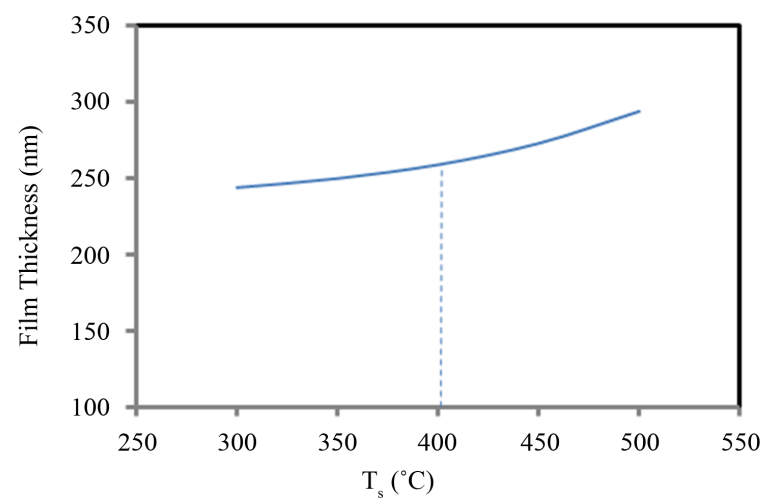

Figure 4. Predicted variation of $\mathrm{ZnO}$ film thickness with substrate temperature $\left(T=400^{\circ} \mathrm{C}, C=0.2 \mathrm{~mol} / \mathrm{lit}\right)$.

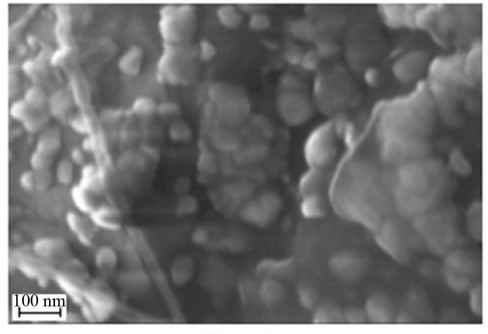

Case 1

(a)

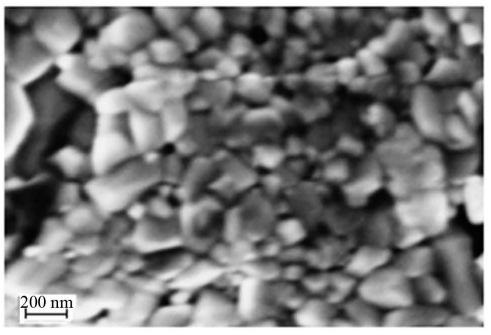

Case 2

(b)

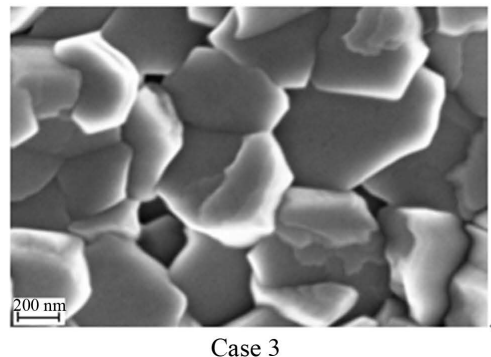

(c)

Figure 5. SEM micrographs of spray pyrolysis deposition of $\mathrm{ZnO}$ thin films on $\mathrm{Al}_{2} \mathrm{O}_{3}$ substrate: (a) $T=400^{\circ} \mathrm{C}$ and $\mathrm{C}$ $=0.1 \mathrm{~mol} / \mathrm{lit}$; (b) $\mathrm{ZnO}$ at $T=400^{\circ} \mathrm{C}$ and $C=0.2 \mathrm{~mol} / \mathrm{lit}$; and (c) $\mathrm{ZnO}$ at $T=400^{\circ} \mathrm{C}$ and $C=0.3 \mathrm{~mol} / \mathrm{lit}$.

xagonal flake morphology similar to a previous study [30]. Upon further increase in concentration $(C=0.3$ $\mathrm{mol} / \mathrm{lit}$ ), the density and size of particles are increased to an average size of $233 \mathrm{~nm}$. In this case, the crystals are plate-like and the sides of the walls are grown packed together (Figure 5(c)). A similar hexagonal wurtzie structure has also been observed at high concentration [1].

Figure 6(a) and Figure 6(b) show the SEM micrographs of $\mathrm{ZnO}+\mathrm{In}_{2} \mathrm{O}_{3}$ mixed oxide thin films on $\mathrm{Al}_{2} \mathrm{O}_{3}$ substrate at $T=400^{\circ} \mathrm{C}$ composed of $25 \%$ of $\mathrm{ZnO}$ mixed with $75 \%$ of $\mathrm{In}_{2} \mathrm{O}_{3}$ (Figure 6(a)), and $80 \%$ of $\mathrm{ZnO}$ mixed with $20 \%$ of $\mathrm{In}_{2} \mathrm{O}_{3}$ (Figure $6(\mathrm{~b})$ ). At lower composition ratio of $\mathrm{ZnO}$ (Figure 6(a)), the growth of particle side walls results in the formation of nano tubes [28] [31]. By increasing the amount of zinc (Figure 6(b)), crystallization is enhanced and a well-structured thin film is synthesized. In this case, there is a better chance to produce $\mathrm{ZnO}$ crystals or rods [28]. This result confirms that the overall particle size is increased when the concentration of $\mathrm{In}_{2} \mathrm{O}_{3}$ is decreased. The observed trend may be attributed to the fact that indium ions limit the growth of $\mathrm{ZnO}$ particles on the surface. The grain size has been observed to decrease by increasing the indium doping [32]. This is attributed to the stresses applied by the mixture which limits the growth of grain size.

The results show that addition of $\mathrm{In}_{2} \mathrm{O}_{3}$ component to $\mathrm{ZnO}$ results in the growth of particles over a wider size range as was also observed in a previous study [33]. Thus the particles are deposited with less homogeneity compared to the single oxide ZnO. A comparison of Figure 6(a) and Figure 6(b) also shows that the film is more homogenous when $\mathrm{ZnO}$ is the dominant precursor. At low concentration of $\mathrm{ZnO}$, the structure of the mixed oxide is similar to that obtained for single oxide $\mathrm{ZnO}$ in Figure 5(c). However the average particle size obtained $(\sim 136 \mathrm{~nm})$ is less than the single oxide. The value predicted from the mathematical model for the mixed oxide of 


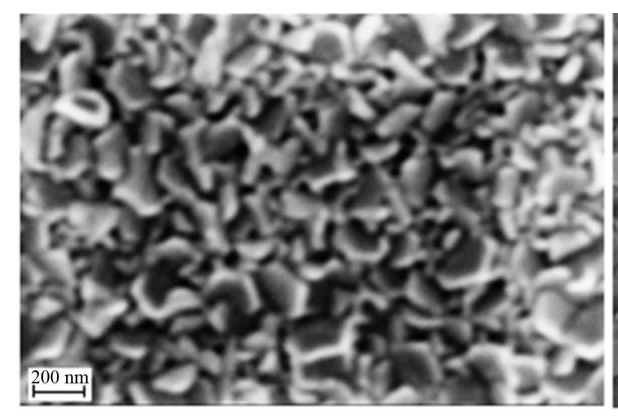

Case 4

(a)

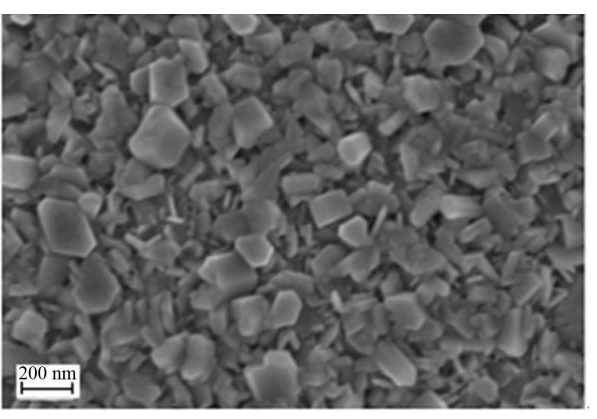

Case

Figure 6. SEM micrographs of spray pyrolysis deposition of $\mathrm{ZnO}+\mathrm{In}_{2} \mathrm{O}_{3}$ thin films on $\mathrm{Al}_{2} \mathrm{O}_{3}$ substrate: (a) $0.25 \mathrm{ZnO}+0.75 \mathrm{In}_{2} \mathrm{O}_{3}$ at $T=400^{\circ} \mathrm{C}$ and $C=0.1 \mathrm{~mol} / \mathrm{lit}$; and (b) $0.8 \mathrm{ZnO}+$ $0.2 \mathrm{In}_{2} \mathrm{O}_{3}$ at $T=400^{\circ} \mathrm{C}$ and $C=0.1 \mathrm{~mol} / \mathrm{lit}$.

Table 4. Predicted and measured particle size for single and mixed oxides.

\begin{tabular}{rccccc}
\hline Case & Deposited oxide & Temperature $\left({ }^{\circ} \mathbf{C}\right)$ & $\begin{array}{c}\text { Concentration } \\
(\mathbf{m o l} / \text { lit) }\end{array}$ & $\begin{array}{c}\text { Measured particle } \\
\text { size (nm) }\end{array}$ & $\begin{array}{c}\text { Predicted particle } \\
\text { size }(\mathbf{n m})\end{array}$ \\
\hline 1 & $\mathrm{ZnO}$ & 400 & 0.1 & 112 & 189 \\
2 & $\mathrm{ZnO}$ & 400 & 0.2 & 119 & 234 \\
3 & $\mathrm{ZnO}$ & 400 & 0.3 & 233 & 265 \\
4 & $25 \mathrm{wt} \% \mathrm{ZnO}+75 \mathrm{wt} \% \mathrm{In}_{2} \mathrm{O}_{3}$ & 400 & 0.1 & 136 & 209 \\
5 & $80 \mathrm{wt} \% \mathrm{ZnO}+20 \mathrm{wt} \% \mathrm{In}_{2} \mathrm{O}_{3}$ & 400 & 0.1 & 201 & 244 \\
\hline
\end{tabular}

Figure 6(a) is $209 \mathrm{~nm}$ which is lower than the corresponding value for ZnO deposition. This value is however still in the range of the measured particle size. The predicted particle size is $244 \mathrm{~nm}$ at the higher concentration of $\mathrm{ZnO}$ (Figure 6(b)). Table 4 summarizes the values of the average particle sizes obtained from modeling and experiments.

The agreement between the experimental measurements and modeling is generally acceptable and the results are on the same order of magnitude. The agreement is particularly good when the deposited film is completely well-structured and the crystal shapes are fully formed as in cases 3 and 5 for which the maximum error is less than $14 \%$ in case 3 .

\section{Discussion}

A comprehensive mathematical model has been developed to simulate film deposition by Spray Pyrolysis Technique (SPT). The mechanism underlying film growth by SPT was systematically investigated, enabling identification of the essential processes necessary for the development of a comprehensive model. Thus, the model was divided into four sub-models: Atomization, Evaporation, Decomposition and Growth based on the underlying physical and chemical mechanisms. The model developed is applicable to the growth of both single oxide (ZnO) and mixed oxide $\left(\mathrm{ZnO}+\mathrm{In}_{2} \mathrm{O}_{3}\right)$. The predicted results (particle size and film thickness) were validated by comparison with the experimental data obtained in a complementary processing study.

The predicted results demonstrate the important roles that temperature, concentration and deposition duration play on film growth. This finding is in agreement with previous studies. The model however extends beyond the experiment by indicating the threshold deposition duration at which the initial rapid film growth seizes and the film thickness stabilizes by diffusion.

The model has been corroborated by the experimental data for both single oxide $(\mathrm{ZnO})$ and mixed oxide ( $\mathrm{ZnO}$ $+\mathrm{In}_{2} \mathrm{O}_{3}$ ) film growth. Both sets of results indicate that by increasing the concentration of precursors, particles grow faster and develop into large-sized crystals. At low concentration, the particles are smaller and the size distribution is less homogeneous. The results also indicate random orientation of crystallites and smaller particle 
sizes at low temperature.

SEM micrographs of synthesized films were used to measure particle size distribution on film surface. The predicted and measured particle size and film thickness are on the same order of magnitude. The accuracy of the model significantly improves at high substrate temperatures for which the reaction rate is close to the stoichiometric condition.

The mathematical model developed could potentially be applied in a variety of situations. For example, the results from the decomposition model can be used to determine the optimum condition to synthesize thin films with homogeneous particle size distribution.

\section{Acknowledgements}

The study was supported by the National Science Foundation under grant number CMMI-1030689, and the Russian Scientific Foundation under grant number 14-19-00781.

\section{References}

[1] Sivalingam, D., Gopalakrishnan, J.B. and Rayappan, J.B.B. (2012) Nanostructured Mixed ZnO and CdO Thin Film for Selective Ethanol Sensing. Materials Letters, 77, 117-120. http://dx.doi.org/10.1016/j.matlet.2012.03.009

[2] Ilican, S., Caglar, Y., Caglar, M. and Yakuphanoglu, F. (2006) Electrical Conductivity, Optical and Structural Properties of Indium-Doped ZnO Nanofiber Thin Film Deposited by Spray Pyrolysis Method. Physica E: Low-Dimensional Systems and Nanostructures, 35, 131-138. http://dx.doi.org/10.1016/j.physe.2006.07.009

[3] Kalantar-Zadeh, K. and Fry, B. (2007) Nanotechnology-Enabled Sensors. Springer, New York.

[4] Kumar, P. (2013) Magnetism and Magnetotransport in Half and over Doped Manganites Impact of Substrate Induced Strain and Polycrystalline Disorder. Ph.D. Thesis, Jaypee Institute of Information Technology, Noida.

[5] Perednis, D. and Gauckler, L.J. (2005) Thin Film Deposition Using Spray Pyrolysis. Journal of Electroceramics, 14, 103-111. http://dx.doi.org/10.1007/s10832-005-0870-x

[6] Nakaruk, A.S.C.C. and Sorrell, C.C. (2010) Conceptual Model for Spray Pyrolysis Mechanism: Fabrication and Annealing of Titania Thin Films. Journal of Coatings Technology and Research, 7, 665-676.

http://dx.doi.org/10.1007/s11998-010-9245-6

[7] Jayanthi, G.V., Zhang, S.C. and Messing, G.L. (1993) Modeling of Solid Particle Formation during Solution Aerosol Thermolysis: The Evaporation Stage. Aerosol Science and Technology, 19, 478-490. http://dx.doi.org/10.1080/02786829308959653

[8] Yu, H.F. and Liao, W.H. (1998) Evaporation of Solution Droplets in Spray Pyrolysis. International Journal of Heat and Mass Transfer, 41, 993-1001. http://dx.doi.org/10.1016/S0017-9310(97)00226-3

[9] Eslamian, M., Ahmed, M. and Ashgriz, N. (2006) Modelling of Nanoparticle Formation during Spray Pyrolysis. Nanotechnology, 17, 1674. http://dx.doi.org/10.1088/0957-4484/17/6/023

[10] Reuge, N. and Caussat, B. (2007) A Dimensionless Study of the Evaporation and Drying Stages in Spray Pyrolysis. Computers \& Chemical Engineering, 31, 1088-1099. http://dx.doi.org/10.1016/j.compchemeng.2006.09.011

[11] Huang, L., Kumar, K. and Mujumdar, A.S. (2004) Simulation of a Spray Dryer Fitted with a Rotary Disk Atomizer Using a Three-Dimensional Computational Fluid Dynamic Model. Drying Technology, 22, 1489-1515. http://dx.doi.org/10.1081/DRT-120038737

[12] Jiang, X., Ward, T.L., Swol, F.V. and Brinker, C.J. (2010) Numerical Simulation of Ethanol-Water-NaCl Droplet Evaporation. Industrial \& Engineering Chemistry Research, 49, 5631-5643. http://dx.doi.org/10.1021/ie902042z

[13] Khatami, S.M.N., Ilegbusi, O.J. and Trakhtenberg, L. (2013) Modeling of Aerosol Spray Characteristics for Synthesis of Sensor Thin Film from Solution. Applied Mathematical Modeling, 37, 6389-6399. http://dx.doi.org/10.1016/j.apm.2013.01.009

[14] Khatami, S.M.N. and Ilegbusi, O.J. (2012) Droplet Evaporation and Chemical Reaction in a Single Multi-Component Droplet to Synthesis Mixed-Oxide Film Using Spray Pyrolysis Method. Proceedings of the ASME 2012 International Mechanical Engineering Congress and Exposition, Houston, 9-15 November 2012, 633-638.

[15] Widiyastuti, W., Wang, W.N., Lenggoro, I.W., Iskandar, F. and Okuyama, K. (2007) Simulation and Experimental Study of Spray Pyrolysis of Polydispersed Droplets. Journal of Materials Research, 22, 1888-1898. http://dx.doi.org/10.1557/jmr.2007.0235

[16] Filipovic, L., Selberherr, S., Mutinati, G.C., Brunet, E., Steinhauer, S., Köck, A. and Schrank, F. (2013) Modeling Spray Pyrolysis Deposition. Proceedings of the World Congress on Engineering, 2, 987-992. 
[17] Blaker, K.A., Halani, A.T., Vijayakumar, P.S., Wieting, R.D. and Wong, B. (1988) Chemical Vapor Deposition of Zinc Oxide Films and Products. US Patent No. 4751149.

[18] Barnes, T.M., Leaf, J., Fry, C. and Wolden, C.A. (2005) Room Temperature Chemical Vapor Deposition of c-Axis ZnO. Journal of Crystal Growth, 274, 412-417. http://dx.doi.org/10.1016/j.jcrysgro.2004.10.015

[19] Khatami, S.M.N., Kuruppumullage, D.N. and Ilegbusi, O.J. (2013) Characterization of Metal Oxide Sensor Thin Films Deposited by Spray Pyrolysis. Proceedings of the ASME 2013 International Mechanical Engineering Congress and Exposition, San Diego, 15-21 November, Article ID: V010T11A044.

[20] Khatami, S.M.N. and Ilegbusi, O.J. 2011) Modeling of Aerosol Spray Characteristics for Synthesis of Mixed-Oxide Nanocomposite Sensor Film. Proceedings of the ASME 2011 International Mechanical Engineering Congress and Exposition, Denver, 11-17 November 2011, 581-589.

[21] Shinde, P.S. (2012) Photoelectrochemical Detoxification of Water Using Spray Deposited Oxide Semiconductor Thin Films. Ph.D. Thesis, Shivaji University, Kolhapur.

[22] Kowarik, S., Hinderhofer, A., Gerlach, A. and Schreiber, F. (2011) Modeling Thin Film Deposition Processes Based on Real-Time Observation. In: Cao, Z., Ed., Thin Film Growth, Woodhead Publishing, Oxford, Cambridge.

[23] Gupta, S.P. (1985) Measures of Dispersion, Statistical Methods. Sultan Chand and Sons, New Delhi.

[24] Ayouchi, R., Martin, F., Leinen, D. and Ramos-Barrado, J.R. (2003) Growth of Pure ZnO Thin Films Prepared by Chemical Spray Pyrolysis on Silicon. Journal of Crystal Growth, 247, 497-504. http://dx.doi.org/10.1016/S0022-0248(02)01917-6

[25] Hu, J. and Gordon, R.G. (1992) Atmospheric Pressure Chemical Vapor Deposition of Gallium Doped Zinc Oxide Thin Films from Diethyl Zinc, Water, and Triethyl Gallium. Journal of Applied Physics, 72, 5381-5392. http://dx.doi.org/10.1063/1.351977

[26] Hu, J. and Gordon, R.G. (1992b) Textured Aluminum-Doped Zinc Oxide Thin Films from Atmospheric Pressure Chemical-Vapor Deposition. Journal of Applied Physics, 71, 880-890. http://dx.doi.org/10.1063/1.351309

[27] Zunke, I., Heft, A., Schäfer, P., Haidu, F., Lehmann, D., Grünler, B. and Zahn, D.R.T. (2013) Conductive Zinc Oxide Thin Film Coatings by Combustion Chemical Vapour Deposition at Atmospheric Pressure. Thin Solid Films, 532, 5055. http://dx.doi.org/10.1016/j.tsf.2012.11.151

[28] Liang, Z., Gao, R., Lan, J.L., Wiranwetchayan, O., Zhang, Q., Li, C. and Cao, G. (2013) Growth of Vertically Aligned ZnO Nanowalls for Inverted Polymer Solar Cells. Solar Energy Materials and Solar Cells, 117, 34-40. http://dx.doi.org/10.1016/j.solmat.2013.05.019

[29] Tucic, A., Marinkovic, Z.V., Mancic, L., Cilense, M. and Miloševic, O. (2003) Pyrosol Preparation and Structural Characterization of $\mathrm{SnO}_{2}$ Thin Films. Journal of Materials Processing Technology, 143, 41-45. http://dx.doi.org/10.1016/S0924-0136(03)00316-9

[30] Jiao, B.C., Zhang, X.D., Wei, C.C., Sun, J., Huang, Q. and Zhao, Y. (2011) Effect of Acetic Acid on ZnO: In Transparent Conductive Oxide Prepared by Ultrasonic Spray Pyrolysis. Thin Solid Films, 520, 1323-1329. http://dx.doi.org/10.1016/j.tsf.2011.04.152

[31] Miki-Yoshida, M., Paraguay-Delgado, F., Estrada-Lopez, W. and Andrade, E. (2000) Structure and Morphology of High Quality Indium-Doped ZnO Films Obtained by Spray Pyrolysis. Thin Solid Films, 376, 99-109. http://dx.doi.org/10.1016/S0040-6090(00)01408-5

[32] Lee, J.H., Lee, S.Y. and Park, B.O. (2006) Fabrication and Characteristics of Transparent Conducting $\mathrm{In}_{2} \mathrm{O}_{3}-\mathrm{ZnO}_{\mathrm{n}} \mathrm{Thin}$ Films by Ultrasonic Spray Pyrolysis. Materials Science and Engineering: B, 127, 267-271. http://dx.doi.org/10.1016/j.mseb.2005.10.008

[33] Badadhe, S.S. and Mulla, I.S. (2009) $\mathrm{H}_{2} \mathrm{~S}$ Gas Sensitive Indium-Doped ZnO Thin Films: Preparation and Characterization. Sensors and Actuators B: Chemical, 143, 164-170. http://dx.doi.org/10.1016/j.snb.2009.08.056 
Scientific Research Publishing (SCIRP) is one of the largest Open Access journal publishers. It is currently publishing more than 200 open access, online, peer-reviewed journals covering a wide range of academic disciplines. SCIRP serves the worldwide academic communities and contributes to the progress and application of science with its publication.

Other selected journals from SCIRP are listed as below. Submit your manuscript to us via either submit@scirp.org or Online Submission Portal.
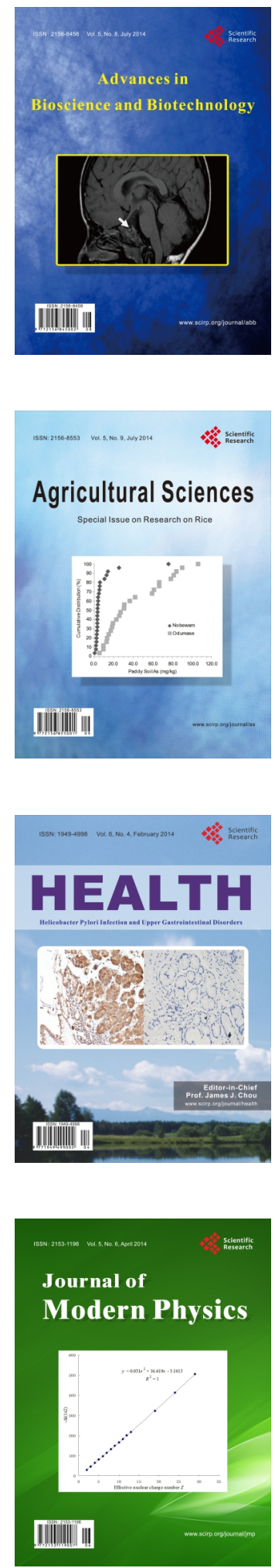
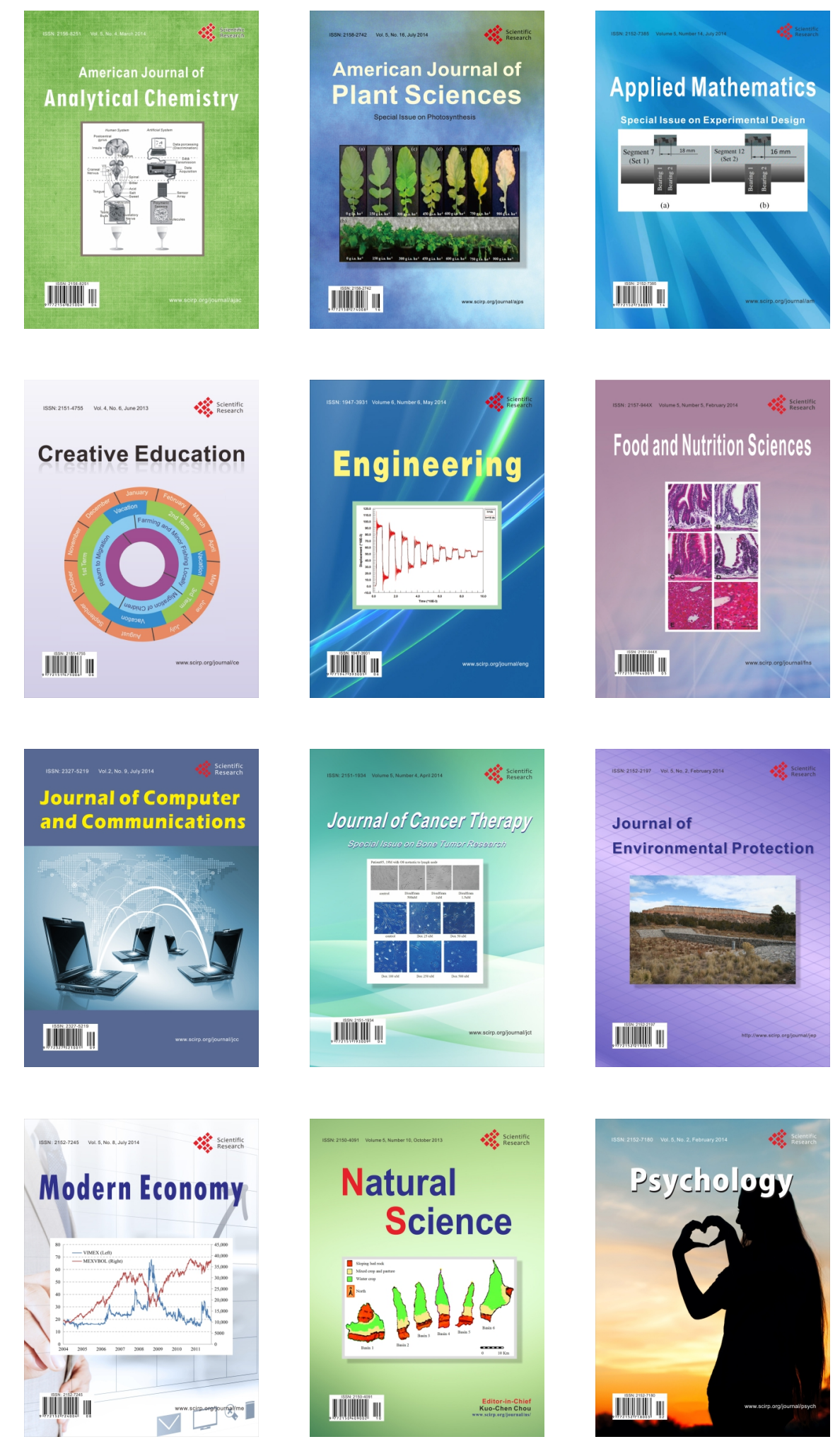